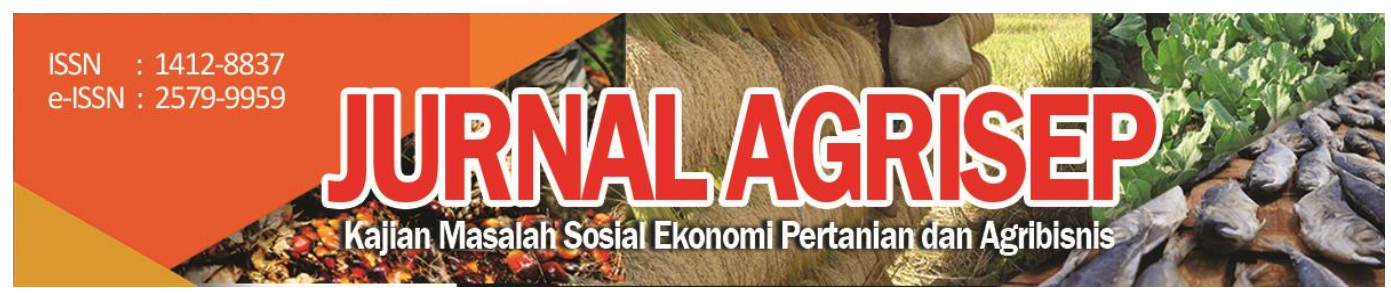

DOI: 10.31186/jagrisep.19.2.241-254

\title{
KARAKTERISTIK PETANI HUTAN DAN RESOLUSI KONFLIK TENURIAL DI HUTAN LINDUNG RIMBO DONOK, KABUPATEN KEPAHIANG, PROVINSI BENGKULU
}

\author{
Characteristics of Forest Farmers and Tenurial Conflicts Resolution in \\ Rimbo Donok Protection Forest, Kepahiang District, Bengkulu Province
}

\author{
Gunggung Senoaji ${ }_{1} \longrightarrow$, Muhamad Fajrin Hidayat'), Iskandar') \\ 1),2) Jurusan Kehutanan Fakultas Pertanian Universitas Bengkulu \\ 3) Fakultas Hukum Universitas Bengkulu \\ Email: senoaji1211@gmail.com
}

\begin{abstract}
Rimbo Donok Protected Forest covers 377,99 hectare area, located in Kepahiang District, Bengkulu Province, Indonesia. The main function of protected forest is to protect life buffer system. Therefore, the land use must be forest. In Rimbo Donok Protected Forest, there has been a change of land use from forest land to crop land. There has been tenurial conflicts in the utilization of forest area. The objective of this study was to determine the characteristics of forest farmer in Rimbo Donok protected forest area and choose to resolve tenurial conflicts. The data of uses were collected through mapping techniques, field observation, and interview. The accidental sampling technique with Slovin Formula was used to select 44 respondents. The results showed that land use of Rimbo Donok Protected Forest in 2016 is entirely crop land. All of this protected forest have been illegaly occupied by people. These people are planting coffe and other agricultural plants in the area. The average land area of head family is 1.33 ha. This conflict resolution of forest utilization should be able to accommodate the socioeconomic function and environmental protection function. Efforts to legalize the utilization of forests should be carried out under various schemes such as: community forest, village forest, or partnership. the agroforestry system can be selected as its land management system.
\end{abstract}

Keywords : Forest Protected, Forest Farmers, Tenurial Conflicts Resolution 


\section{ABSTRAK}

Hutan Lindung Rimbo Donok memiliki luas 377,99 ha, terletak di Kabupaten Kepahiang Provinsi Bengkulu. Fungsi utama dari hutan lindung ini adalah sebagai sistem penyangga kehidupan untuk mengatur tata air, mencegah banjir dan erosi, dan menjaga kesuburan tanah. Seharusnya, tutupan vegetasi kawasan hutan ini berupa hutan primer. Namun fakta di lapangan, seluruh kawasan hutan ini telah berubah menjadi lahan pertanian yang digarap oleh para petani hutan secara ilegal. Kondisi ini mengindikasikan terjadi konflik tenurial. Penelitian ini bertujuan untuk mengetahui karakteristik petani hutan dan penyelesaian konflik tenurial di kawasan hutan lindung Rimbo Donok. Metode penelitian yang digunakan adalah teknik pemetaan, pengamatan lapangan dan wawancara. Responden petani hutan jumlahnya 44 orang yang dipilih menggunakan teknik accedental samping dengan rumus Slovin. Hasil penelitian menunjukkan bahwa penggunaan lahan di hutan lindung Rimbo Donok seluruhnya berupa lahan pertanian, yang digarap masyarakat secara tidak sah dengan menanam kopi dan tanaman pertanian lainnya. Rata-rata luas lahan garapan untuk setiap kepala keluarga sekitar 1,33 ha. Ini berarti telah terjadi konflik tenurial antara pemerintah dan masyarakat petani hutan. Upaya legalisasi pemanfatan hutan harus dilakukan dengan berbagai skema pengelolaan seperti : hutan kemasyarakatan, hutan desa, atau kemitraan. Pengolahan lahannya dapat menggunakan sistem agroforestri.

Kata Kunci: Hutan Lindung, Petani Hutan, Resolusi Konflik Tenurial

\section{PENDAHULUAN}

Hutan merupakan sumber daya alam dengan fungsi utamanya sebagai pengendali ekosistem bumi (Simon, 2001). Hutan berperan penting dalam mengatur tata air (Asdak, 2004: Ulya, dkk, 2014;), gudang plasma nutfah dan menjaga kesuburan tanah (Indriyanto, 2006), dan menyerap karbon dioksida di udara (Wibowo, 2013). Selain untuk perlindungan lingkungan, hutan juga berfungsi sebagai sumber ekonomi bagi manusia, seperti sumber pangan (Dwiprabowo, dkk, 2011), penghasil kayu (Rahmat, 2011; Hidayat, 2015), barang tambang (Zubayr, dkk, 2014), dan ekowisata (Supyan, 2011).

Untuk mengakomodir fungsi perlindungan lingkungan dan ekonomi hutan, dalam Undang-Undang No. 41 tahun 1999 tentang Kehutanan, pemerinah mengklasifikasikan kawasan hutan menjadi hutan konservasi, hutan lindung, dan hutan produksi. Hutan lindung merupakan kawasan hutan yang mempunyai fungsi pokok sebagai perlindungan sistem penyangga kehidupan untuk mengatur tata air, mencegah banjir, mengendalikan erosi, mencegah intrusi air laut, dan memelihara kesuburan tanah. Salah satu kawasan hutan lindung yang berada di Provinsi Bengkulu adalah Hutan Lindung Rimbo Donok (Register 8) di Kabupaten Kepahiang.

Hutan Lindung Rimbo Donok telah ditetapkan sebagai kawasan hutan lindung berdasarkan Surat Keputusan Menteri Kehutanan No. 3982/Menhut- 
VII/KUH/2014 tanggal 23 Mei 2014 dengan luas kawasan 377,99 ha (Dinas Lingkungan Hidup dan Kehutanan, 2017). Penetapan kawasan Hutan Lindung Rimbo Donok ini ditujukan sebagai sistem penyangga kehidupan bagi masyarakat yang tinggal di sekitar daerah aliran sungai Hulu Musi, Kabupaten Kepahiang. Idealnya tutupan vegetasinya berupa hutan primer. Namun kenyataan di lapangan, seluruh tutupan vegetasinya telah berubah menjadi lahan pertanian kering campur.

Fungsi hutan lindung sebagai sistem penyangga kehidupan sudah tidak berjalan dengan baik. Perubahan tutupan vegetasi di hutan lindung mulai terjadi ketika kepemilikan lahan pertanian masyarakat mulai menyempit. Pertambahan penduduk yang terus menerus menyebabkan tekanan masyarakat terhadap kawasan hutan semakin tinggi, sedangkan penegakan hukum bagi para perambah hutan belum berjalan maksimal (Kaimuddin, 2008). Ketergantungan masyarakat ke dalam kawasan hutan menjadi tinggi (Yusran dan Abdulah, 2007). Ketergantungan masyarakat hutan dalam memanfaatkan hutan tidak seluruhnya dipayungi oleh aturan hukum. Masih banyak masyarakat yang mengolah lahan hutan secara ilegal. Klaim terhadap lahan garapan sebagai tanah adat yang merupakan warisan leluhur dijadikan alasan untuk memanfatkan kawasan hutan. Tindakan yang dilakukan masyarakat dengan memanfaatkan hutan lindung sebagai lahan pertanian secara tidak sah merupakan tindakan penyerobotan kawasan hutan, sehingga menimbulkan konflik dengan pengelola kawasan hutan (Dassir, 2008).

Konflik merupakan benturan yang terjadi antara dua pihak atau lebih yang disebabkan karena adanya perbedaan kondisi sosial budaya, nilai, status, dan kekuasaan (Fuad dan Maskanah, 2000); atau persepsi mengenai perbedaan kepentingan (Pruitt dan Rubin, 2009). Konflik tenurial adalah konflik dalam penguasaan lahan dan sumber daya alam (Sylviani dan Hakim, 2014). Konfik tenurial pada kawasan hutan berarti terjadi benturan dalam penguasaan lahan dan sumber daya di dalam kawasan hutan, seperti konflik pemanfaatan kawasan hutan untuk areal pemukiman, jalan, ladang dan kebun (Dassir, 2008). Konflik ini muncul dari persepsi dan interpretasi yang berbeda antar pihak terhadap hak mereka atas tanah dan sumber daya hutan (Safitri dkk, 2011).

Pemanfaatan kawasan hutan oleh masyarakat harus mendapat ijin dari pemerintah karena hutan merupakan public goods yang mempunyai multi fungsi. Pemanfaatan lahan hutan tanpa ijin merupakan pelanggaran hukum sesuai dengan pasal 50 Undang-Undang No. 41 tahun 1999 tentang kehutanan. Kawasan Hutan Lindung Rimbo Donok telah digarap oleh masyarakat menjadi lahan pertanian. Penelitian ini bertujuan untuk mengetahui karakteristik masyarakat petani hutan dan alternatif resolusi konflik tenurial di kawasan Hutan Lindung Rimbo Donok. 


\section{METODE PENELITIAN}

Penelitian ini dilakukan di Kawasan Hutan Lindung Rimbo Donok, Kabupaten Kepahiang, Provinsi Bengkulu, selama 3 bulan dari April-Juni. Pengumpulan data dilakukan dengan teknik pemetaan, wawancara dan pengamatan lapangan.

Pemetaan dilakukan untuk mengetahui kondisi penggunaan lahan aktual, dengan menggunakan peta tutupan lahan, liputan tahun 2017 dari Kementerian Lingkungan Hidup dan Kehutanan. Teknik wawancara dilakukan terhadap masyarakat yang menjadi responden penelitian. Respondennya adalah masyarakat yang menggarap kawasan hutan. Pemilihan responden dilakukan metode insidental sampling di lokasi penelitian, yakni pemilihan sampel dengan memilih para penggarap lahan yang secara kebetulan ditemui di lokasi penelitian dan dipandang sesuai sebagai sumber data. Kriteria responden yang terpilih adalah : masyarakat dewasa, memiliki lahan garapan di Hutan Lindung Rimbo Donok, dan sehat jasmani-rohani. Pengamatan lapangan dilakukan pada lahan garapan yang dikelola oleh para responden, meliputi : letak dan luas lahan garapan, jenis tanaman yang tumbuh, dan pola tanamnya. Jumlah respondennya sebanyak 44 orang, ditentukan dengan menggunakan rumus Slovin (Nazir, 2009).

$$
\mathrm{n}=(0.25)\left(\frac{Z_{\alpha / 2}}{\varepsilon}\right)^{2}
$$

dimana $: \mathrm{n}=$ jumlah responden; $\mathrm{Za} / 2=$ nilai dari tabel normal atas tingkat keyakinan $=1,96 ; \varepsilon=$ kesalahan penarikan $/$ margin of error $=15 \%$.

Data dan informasi yang dikumpulkan dianalisis dengan analisis sistem informasi geografis (SIG) dan analisis deskriptif kualitatif-kuantitatif. Data yang dianalisis secara deskriptif kuantitatif-kualitatif meliputi kondisi sosial dan ekonomi, letak dan luas lahan garapan, status lahan garapan, pola pemanfaatan lahan, dan jenis tanaman di lahan garapan.

\section{HASIL DAN PEMBAHASAN}

\section{Kondisi Hutan Lindung Rimbo Donok}

Hasil analisis citra satelit terhadap tutupan vegetasi yang dirilis dari Badan Planologi dan Tata Lingkungan Kementerian Lingkungan Hidup dan Kehutanan tahun 2017, menunjukkan bahwa tutupan vegetasi Hutan Lindung Rimbo Donok, seluruhnya berupa lahan pertanian kering campur. Ini berarti seluruh kawasan hutannya telah berubah menjadi lahan garapan masyarakat. Fungsi perlindungan kawasan hutan lindung ini telah berubah menjadi fungsi sosial ekonomi masyarakat. Menurut Senoaji (2009), cukup banyak kawasan 
hutan lindung yang telah dimanfaatkan masyarakat untuk kepentingan lain diluar fungsi perlindungan, seperti untuk lahan kebun, ladang, pemukiman, dan sawah. Kondisi ini menunjukkan bahwa telah terjadi aktifitas perambahan hutan lindung oleh masyarakat. Perambahan kawasan hutan merupakan hal yang biasa terjadi pada wilayah yang berbatasan dengan kawasan hutan dan berpotensi tetap berlanjut karena penegakan hukum kasusnya belum maksimal (Kaimuddin, 2008). Besarnya kontribusi pendapatan masyarakat sekitar hutan dari dalam kawasan hutan lindung di Hutan Lindung Bukit Daun Kabupaten Rejang Lebong mencapai 52,5 \% (Senoaji, 2009), yang terkait dengan usaha tani masyarakat di dalam kawasan hutan (Supratman, 2007).

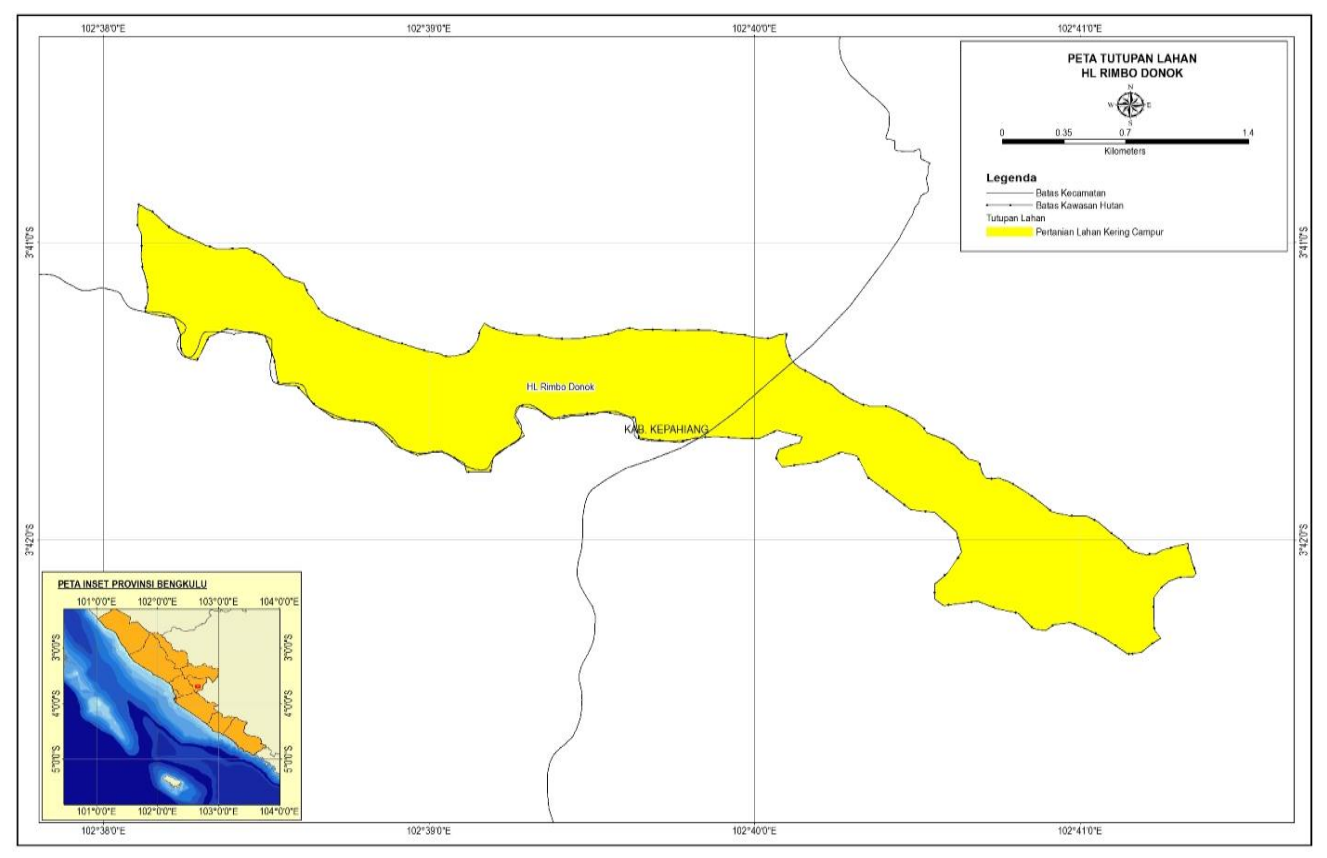

\section{Gambar 1.}

Peta penggunaan lahan di Kawasan Hutan Lindung Rimbo Donok

Dari Gambar 1, dapat dijelaskan bahwa pengunaan lahan di kawasan Hutan Lindung Rimbo Donok, seluruhnya berupa pertanian lahan kering campur. Kawasan hutan lindung akan berfungsi optimal sebagai sarana perlindungan lingkungan jika bervegetasi pohon seperti hutan alam yang memiliki strata tajuk dan perakaran yang bertingkat (Simon, 2007). Mengingat kawasan hutan ini fungsinya sebagai hutan lindung yang melindungi areal di bagian hilirnya, maka perlu dilakukan upaya untuk mengembalikan fungsi lindungnya dengan tetap memperhatikan petani hutan yang telah terlanjur mengelolanya, melalui kebijakan pengelolaan hutan lindung yang berbasis pemberdayaan masyarakat. 
Petani hutan di hutan lindung ini, menanam kopi (Coffea canephora) sebagai tanaman pokoknya. Jenis tanaman sisipan lainnya yang ditanam para petani hutan untuk pemenuhan kebutuhan sehari-hari, di antaranya adalah : cabe (Capsium frutesces), pepaya (Carica papaya), buncis (Phaseolus vulgaris), jahe (Zingiber officinale), kacang panjang (Vigna sinensis), lengkuas (Languasa galanga), tomat (Solanum lycopersicum), lada (Piper nigrum), serai (Cymbopogan citratus), pisang (Musa spp), tebu (Saccharum officinarum), terung (Sonamum melongena), labu kuning (Cucurbita moschata) nanas (Ananas comosus), kunyit (Curcuma longa), daun bawang (Allium fistulosum), ubi kayu (Manihot esculenta), dan buah naga (Hylocereus undatus). Pada beberapa lahan garapan petani, ditemukan juga beberapa jenis pohon penghasil buah atau sebagai pelindung seperti : alpokat (Persea gratissima), lamtoro (Leucaena leucochepala), durian (Durio spp), aren (Arenga pinata), kelapa (Cocos nucifera), mangga (Mangifira indica), merambung (Vernonia arborea), bambang lanang (Madhuca aspera), kapuk (Ceiba pentandra), bambu (Bambuseae sp.), petai (Parkia speciosa), dan kayu res (Gliricidia sepium). Kawasan hutan yang sudah terdesak oleh perkebunan kopi, hanya menyisakan sedikit tegakan pepohonan sebagai penghasil kayu bahan bangunan (Hidayat, 2012).

Kawasan Hutan Lindung Rimbo Donok, seakan-akan telah berubah menjadi lahan pertanian penghasil pangan bagi masyarakat petani hutan dan menjadi rumah kedua bagi mereka. Para petani hutan tersebut membangun "pondok kebun" dengan tempat penjemuran kopi di setiap lahan garapannya. Pada hari-hari di luar musim panen, para petani penggarap akan pulang-pergi ke desanya dalam mengelola lahan garapannya. Pada musim panen kopi, mereka akan tinggal di "pondok kebunnya" sekitar 3-4 bulan dalam setahun. Mereka akan kembali ke desanya jika panen kopi telah selesai dengan membawa hasil panen kopi yang sudah kering dan siap dijual. Perilaku masyarakat petani hutan dalam menggarap dam mengelola hutan lindung ini telah dianggap menjadi hal yang lumrah atau biasa di kehidupannya, padahal bertentangan dengan regulasi atau aturan normatif yang berlaku. Perilaku masyarakat seperti ini dipengaruhi oleh pengalaman individu, motivasi, norma subyektif, dan keyakinannya (Azwar, 2010). Perilaku masyarakat petani hutan ini berbeda dengan perilaku masyarakat Baduy dalam mengelola lahan garapannya yang dilakukan secara legal (Senoaji, 2011).

\section{Karakteristik petani hutan di Hutan Lindung Rimbo Donok}

\section{Tingkat pendidikan}

Tingkat pendidikan mempengaruhi seseorang dalam kemampuan berpikir (Adhawati, 1997). Pendidikan dipandang tidak hanya dapat menambah pengetahuan tetapi juga dapat meningkatkan keterampilan tenaga kerja sehingga akan meningkatkan produktivitas. 
Tabel 1. Karakteristik petani hutan berdasarkan tingkat pendidikan

\begin{tabular}{clcc}
\hline No & Tingkat pendidikan & Jumlah responden & Persen (\%) \\
\hline 1. & Tidak sekolah & 1 & 2,27 \\
2. & SD & 17 & 38,64 \\
3. & SLTP & 15 & 34,09 \\
4. & SLTA & 10 & 22,73 \\
5. & Perguruan tinggi & 1 & 2,27 \\
\hline Jumlah & & 44 & 100,00 \\
\hline
\end{tabular}

Sumber : data primer, 2017

Petani penggarap lahan kawasan Hutan Lindung Rimbo Donok sebagian besar berpendidikan Sekolah Dasar (38,64\%) dan SLTP (34,09\%). Angka ini memberikan indikasi bahwa tingkat pendidikan para petani penggarap ini masih rendah.

\section{Luas lahan garapan}

Luas lahan garapan merupakan modal petani dalam mengembangkan usaha taninya. Pendapatan petani dari usaha tani sangat ditentukan oleh luas lahan garapannya, karena dapat mempengaruhi produksi hasil tani per satuan luas. Purwanti (2007) mengelompokan luas lahan garapan menjadi : "sedikit" jika luasnya kurang dari 1 ha, "sedang" jika luasnya 1 - 3 ha, dan "banyak" jika luasnya lebih dari 3 ha. Karakteristik petani hutan berdasarkan luas lahan garapannya, disajikan disajikan pada tabel berikut.

Tabel 2. Karakteristik responden berdasarkan luas lahan garapan

\begin{tabular}{cccc}
\hline No. & \multicolumn{1}{c}{ Luas lahan garapan } & Jumlah responden & Persen (\%) \\
\hline 1. & Sedikit ( kurang dari1 ha) & 1 & 2,27 \\
2. & Sedang (antara 1-3 ha) & 43 & 97,73 \\
3. & Banyak (lebih dari 3 ha) & 0 & 0,00 \\
\hline Jumlah & 44 & 100,00 \\
\hline
\end{tabular}

Sumber data primer, 2017

Dari Tabel 2, diketahui bahwa sebagian besar $(97,73 \%)$ luas lahan garapan petani hutan termasuk dalam kategori sedang. Hanya 2,27 \% yang memiliki luas lahan garapan kurang dari 1 ha. Rata-rata luas lahan garapan di dalam hutan lindung ini untuk setiap kepala keluarga adalah 1,33 ha. Dengan luas kawasan hutan sekitar 378 ha, diperkirakan terdapat 280 kepala keluarga yang menggarap. Masyarakat petani hutan yang memiliki lahan pertanian sebagai hak milik hanya 4,54\%; selebihnya $(95,46 \%)$ tidak memiliki lahan milik, sehingga sumber pendapatan para petani hutan ini sangat tergantung kepada lahan garapan yang berada di dalam kawasan hutan lindung. 


\section{Cara mendapatkan lahan garapan}

Lahan garapan yang diolah petani merupakan kawasan Hutan Lindung Rimbo Donok. Secara yuridis, lahan ini merupakan milik negara yang kewenangan pengelolaannya diserahkan kepada pemerintah Provinsi Bengkulu. Berdasarkan regulasi yang berlaku dalam Undang-Undang No. 41 tahun 1999 pasal 50 ayat 3 butir (a), disebutkan bahwa setiap orang dilarang mengerjakan dan atau menggunakan dan atau menduduki kawasan hutan secara tidak sah. Fakta di lapangan, hampir seluruh kawasan hutan lindung ini, telah dimanfaatkan oleh masyarakat sebagai lahan pertanian. Masyarakat penggarap menganggap bahwa lahan garapannya adalah milik sah mereka yang diperolehnya melalui berbagai cara., yakni mulai dari membuka lahan sendiri, membeli, warisan dari orang tua dan menyewa dari pemiliknya.

Tabel 3. Karakteristik petani hutan berdasarkan cara memperoleh lahan

\begin{tabular}{clcc}
\hline No & Cara memperoleh lahan & Jumlah responden & Persen (\%) \\
\hline 1. & Menyewa & 6 & 13,64 \\
2. & Membuka sendiri & 1 & 2,27 \\
3. & Warisan & 12 & 27,27 \\
4. & Membeli & 25 & 56,82 \\
\hline Jumlah & 44 & 100,00 \\
\hline
\end{tabular}

Sumber : data primer, 2017

Dari Tabel 3, dijelaskan bahwa sebanyak 13,64\% petani hutan ini memperoleh lahan garapannya dengan cara menyewa kepada masyarakat yang dianggap memiliki lahan garapan; 27,27\% memperoleh lahan garapannya dari pemberian atau warisan orang tuanya; 56,82\% memperoleh lahan garapannya dengan cara membeli kepada pemilik sebelumnya; dan hanya $2,27 \%$ memperoleh lahan garapannya dengan membuka lahan sendiri. Di tingkat masyarakat telah terjadi kesepakatan di antara mereka tentang status kepemilikan lahan garapan di dalam kawasan hutan.

\section{Domisili petani penggarap}

Program pemerintah tentang pemberdayaan masyarakat sekitar hutan melalui skema hutan kemasyarakatan, hutan desa, dan kemitraan hutan, hanya ditujukan bagi masyarakat yang berdomisili di desa-desa sekitar hutan. Desadesa yang berada di sekitar Hutan Lindung Rimbo Donok Kabupaten Kepahiang adalah : Talang Karet, Peraduan Binjang, Tebing Penyamun, Penanjung Panjang dan Air Pauh. Terdapat $72,72 \%$ petani penggarap yang berdomisili di desa-desa sekitar hutan. Karakteristik petani hutan berdasarkan domisilinya disajikan pada Tabel 4 . 
Tabel 4. Karakteristik petani hutan berdasarkan lokasi domisili

\begin{tabular}{llcc}
\hline No & \multicolumn{1}{c}{ Status desa } & Jumlah responden & Persen (\%) \\
\hline 1. Desa sekitar hutan & 32 & 72,72 \\
2. & Desa bukan sekitar hutan & 12 & 27,28 \\
\hline Jumlah & 44 & 100,00 \\
\hline sumber : data primer, 2017 &
\end{tabular}

\section{Resolusi Konflik Tenurial Kawasan Hutan}

Konflik pengelolaan sumberdaya hutan disebabkan karena keterbatasan sumberdaya hutan sedangkan kebutuhannya selalu meningkat, bertambahnya jumlah penduduk yang memunculkan berbagai kepentingan atas sumberdaya yang sama, dan perubahan kondisi sosial, ekonomi, budaya, hukum dan politik yang menciptakan kepentingan dan kebutuhan baru terhadap sumberdaya hutan (Fuad dan Maskanah, 2000). Konflik tenurial ini digambarkan sebagai fenomena yang terjadi akibat dominasi pemerintah sebagai pemegang kekuasaan yang melahirkan perlawanan masyarakat. Kekuasaan pemerintah sebagai representasi negara melalui kebijakan dan penerapannnya serta implikasinya dalam pengelolaan hutan seringkali berlawanan dengan peran dan kepentingan masyarakat lokal yang tinggal di sekitar kawasan hutan (Maring, 2013).

Perbedaan persepsi, kepentingan, dan hak kepemilikan atas lahan hutan, menjadi penyebab terjadinya konflik antara masyarakat petani hutan dan pemerintah. Perbedaan persepsi terjadi ketika pihak pengelola menganggap bahwa lahan yang digarap merupakan kawasan hutan lindung, sedangkan pihak petani hutan mengganggap bahwa lahannya merupakan lahan garapan yang diperoleh melalui mekanisme transaksi dengan pihak lain. Konflik pemerintah dengan masyarakat sekitar hutan sering terjadi karena selama ini pembangunan kehutanan belum memperhatikan kondisi sosial ekonomi budaya masyarakat. Ketertinggalan dari segi ekonomi menyebabkan timbul sikap resistensi dari masyarakat terhadap pihak luar yang mengelola hutan. Sikap inilah yang merupakan potensi terjadinya konflik dalam pengelolaan sumberdaya hutan (Nugraha, 1999). Menurut Darusman (1993), masyarakat di sekitar hutan harus lebih diperhatikan dalam pembangunan sektor kehutanan, karena mereka adalah bagian atau unsur dari ekosistem hutan yang saling tergantung satu sama lainnya.

Menurut Maring (2013), keberadaan hutan sebagai sumberdaya alam tidak bisa dijauhkan dari akses dan peran masyarakat lokal yang tinggal di dalam dan di sekitar hutan. Ironinya, kebijakan pengelolaan hutan di Indonesia memberikan akses yang kecil kepada masyarakat yang tinggal di dalam dan sekitar kawasan hutan. Akibat kebijakan pengelolaan hutan yang tidak memperhatikan dan mengadopsi sistem pengelolaan hutan yang 
dikembangkan masyarakat adalah terjadinya kemunduran pengelolaan hutan oleh masyarakat lokal. Kemunduran pengelolaan hutan juga merupakan akibat dari berbagai distorsi yang ditunjukkan aparat kehutanan dan pengusaha hutan, yang akhirnya masyarakat lokal ikut berperan juga dalam pemanfaatan lahan hutannya secara ilegal.

Hasil penelitian di Hutan Lindung Rimbo Donok, menunjukkan bahwa seluruh petani hutan tidak memiliki ijin pemanfaatan. Mereka secara illegal memanfaatkan kawasan hutan untuk lahan garapan. Motivasinya adalah untuk memenuhi kebutuhan hidupnya sehari-hari. Hutan telah menjadi sumber pangan dan pendapatan bagi masyarakat petani hutan. Kawasan hutan lindungnya tidak lagi berfungsi sebagai perlindungan lingkungan; padahal penetapan hutan lindung diutamakan sebagai sistem penyangga kehidupan, seperti mencegah banjir, erosi, dan menjaga kesuburan tanah.

Pemerintah harus segera menerapkan kebijakan yang dapat meningkatkan fungsi hutan lindung sebagai perlindungan lingkungan, namun dengan tetap mengakomodir keberadaan masyarakat di hutan lindung ini. Tindakan penggusuran dan pengusiran para petani penggarap dari dalam hutan lindung, bukanlah solusi yang tepat, karena mereka menggantungkan hidupnya dari kawasan hutan. Legalitas para penggarap lahan hutan perlu dilakukan untuk keberlanjutan pemanfaatannya dan meningkatkan fungsi lindung. Ketergantungan dan tekanan yang tinggi masyarakat terhadap kawasan hutan, membuat pemerintah mencari berbagai skema pemanfaatan hutan oleh masyarakat. Berbagai kebijakan pemerintah yang berhubungan dengan pemberdayaan masyarakat sekitar hutan yang dapat dipakai untuk legalisasi pemanfaatan kawasan hutan di Hutan Lindung Rimbo Donok adalah : hutan kemasyarakatan, hutan desa, dan kemitraan kehutanan, sesuai dengan Peraturan Menteri Lingkungan Hidup dan Kehutanan Nomor 83 tahun 2016 tentang Perhutanan Sosial. Kementerian kehutanan telah melakukan revitalisasi dalam pengelolaan kawasan hutan melalui program sosial forestry dengan berbagai pola pemberdayaan masyarakat (Heryatna, dkk., 2015).

Prinsip dasar dari skema-skema pemberdayaan masyarakat adalah mengijinkan masyarakat sekitar hutan untuk memanfaatkan lahan hutan melalui pengaturan pola dan jenis tanaman. Para petani penggarap diharuskan menanam tanaman kehutanan di samping tanaman pertanian. Sistem agroforestri merupakan pilihan yang tepat untuk menentukan pola tanamnya, yakni mengkombinasikan tanaman kehutanan (pohon) dengan tanaman pertanian. Pengolahan lahan dengan sistem agroforestri dapat mempertahankan jumlah dan keragaman produksi lahan, sehingga berpotensi memberikan manfaat sosial, ekonomi, dan lingkungan (Hairiah, dkk., 2004). Manfaat dari sisi ekonomi adalah sebagai salah satu sumber pendapatan masyarakat; sedangkan dari sisi ekologi dapat meningkatkan kesuburan lahan dan perlindungan lingkungan (Senoaji, 2012). 
Agroforestri merupakan manajemen pemanfaatan lahan secara optimal dan lestari dengan cara mengkombinasikan kegiatan kehutanan dan pertanian pada unit pengelolaan lahan yang sama dengan memperhatikan kondisi lingkungan fisik, sosial, ekonomi, dan budaya masyarakat (Nair, 1993). Teknik agroforestri akan menekankan penggunaan jenis-jenis pohon serbaguna dan menentukan asosiasi antara jenis-jenis vegetasi yang ditanam. Dalam konteks agroforestri, pohon serbaguna mengandung pengertian semua pohon atau semak yang digunakan atau dikelola untuk lebih dari satu kegunaan produk atau jasa; yang penekanannya pada aspek ekonomis dan ekologis. Saat ini agroforestry diyakini secara luas mempunyai potensi besar sebagai alternatif pengelolaan lahan yang utama untuk konservasi tanah dan juga pemeliharaan kesuburan dan produktifitas lahan di daerah tropis. Keyakinan ini didasarkan pada hipotesa bahwa pohon dan vegetasi besar lainnya dapat meningkatkan kesuburan tanah di bawahnya (Nair, 1993). Sistem agroforestri di kawasan hutan lindung akan meningkatkan kualitas perlindungan lingkungan, memperbaiki produktivitas lahan, dan dapat meningkatkan kesejahteraan petani hutan (Triwanto, dkk. 2012), serta sesuai dilakukan pada lahan kritis pada berbagai kondisi landscape (Bukhari dan Febryano, 2009) seperti halnya di kawasan hutan lindung.

\section{SIMPULAN DAN SARAN}

\section{Simpulan}

Hutan Lindung Rimbo Donok telah ditetapkan oleh pemerintah dengan fungsi utama sebagai sistem penyangga kehidupan melalui pengatur tata air, penyerap karbon, dan mencegah banjir-longsor bagi masyarakat yang tinggal di sekitar daerah aliran sungai Hulu Musi, Kabupaten Kepahiyang. Namun, tutupan vegetasi hutan lindung ini telah berubah nenjadi lahan pertanian kering campur akibat kegiatan pembukaan lahan hutan oleh masyarakat sekitar yang sebagian besar tidak memiliki lahan hak milik. Kawasan hutan lindung ini telah menjadi sumber pangan dan pendapatan bagi masyarakat penggarapnya. Telah terjadi konflik tenurial antara masyarakat dengan pengelola kawasan hutan. Pengusiran dan penggusuran masyarakat penggarap dari dalam kawasan hutan lindung hanya akan menimbulkan masalah sosial baru, yakni meningkatnya kemiskinan bagi masyarakat sekitar hutan. Pemberdayaan masyarakat sekitar hutan melalui skema hutan kemasyarakatan, hutan desa, atau kemitraan hutan, diharapkan dapat menjadi resolusi konflik tenurial ini. Skema pemberdayaan masyarakat ini akan melegalkan kegiatan petani hutan sehingga dapat menciptakan ekosistem lahan garapannya menyerupai ekosistem hutan, melalui penerapan sistem agroforestri. 


\section{Saran}

Hasil kajian ini diharapkan dapat digunakan sebagai masukkan dan bahan pertimbangan oleh berbagai pihak yang memiliki kepentingan dalam pembangunan kehutanan. Gambaran karakteristik petani hutan dan resolusi konflik diharapkan akan menjadi referensi untuk mewujudkan pengelolaan hutan yang mengakomodir fungsi perlindungan lingkungan dan fungsi ekonomi masyarakat.

\section{DAFTAR PUSTAKA}

Adhawati, S.S., 1997. Analisis Ekonomi Pemanfaatan Lahan Pertanian Dataran Tinggi di Desa Parigi (Hulu DAS Malino) Kabupaten Goa. Thesis Program Pasca Sarjana Universitas Hasanudin. Makasar.

Asdak, C., 2004. Hidrologi dan Pengelolaan Daerah Sungai. Gadjah Mada University Press. Yogyakarta.

Azwar, S., 2010. Sikap Manusia, Teori dan Pengukurannya. Edisi ke-2. Pustaka Pelajar. Yogyakarta.

Bukhari dan Febryano, I.G., 2009. Desain Agroforestry pada Lahan Kritis (Studi Kasus di Kecamatan Indrapuri Kabupaten Aceh Besar). Jurnal Perennial, 6 (1) : 53-59.

Dassir, M., 2008. Resolusi Konflik Pemanfaatan Lahan Masyarakat dalam Kawasan Hutan di Kabupaten Luwu Timur. Jurnal Hutan dan Masyarakat III (1):1-10.

Darusman, D., 1993. Pemukiman Perambah Hutan yang Berwawasan Pembangunan Wilayah. Makalah pada Diskusi Terbatas Pemukiman Masyarakat Perambah Hutan, Departemen Transmigrasi dan Pemukiman Perambah Hutan, 4 Mei 1993. Jakarta.

Dinas Lingkungan Hidup dan Kehutanan, 2017. Laporan Review Rencana Tata Ruang Wilayah Provinsi Bengkulu Bidang Kehutanan Tahun 2017. Bengkulu.

Dwiprabowo, H, Effendi, R, Hakim, I, dan Bangsawan, I., 2011. Kontribusi Kawasan Hutan dalam Menunjang Ketahanan Pangan : Studi kasus Provinsi jawa Barat. Jurnal Analisis Kebijakan Kehutanan. 8 (1) : 47-61.

Fuad, F. dan Maskanah, S., 2000. Inovasi Penyelesaian Sengketa Pengelolaan Sumber Daya Hutan. Pustaka LATIN. Bogor.

Hairiah, K, D. Suprayogo, dan M.V. Noordwijk, 2004. Ketebalan Serasah sebagai Indikator Daerah Aliran Sungai (DAS) yang Sehat. Word Agroforestry Center. Bogor. 
Heryatna, D., Zainal, S., Husni, H., 2015. Persepsi Masyarakat terhadap Keberadaan Hutan Kemasyarakatan di Desa Meragun Kecamatan Nangan Taman Kabupaten Sekadau. Jurnal Hutan Lesari IV (1) : 58-64.

Indriyanto, 2006. Ekologi Hutan. Penerbit Bumi Aksara. Jakarta.

Hidayat, S., 2012. Komposisi dan Struktur Tegakan Penghasil Kayu Bahan Bangunan di Hutan Lindung Tanjung Tiga Muara Enim Sumatera Selatan. Jurnal Manusia dan Lingkungan, 22 (2) : 194-200.

Kaimuddin, 2008. Analisa Perambahan Kawasan Hutanterhadap Kebocoran Karbon dan Perubahan Iklim. Jurnal Hutan dan Masyarakat 3 (2):119123.

Maring, P., 2013. Kekuasaan dan Kjonflik Sosial : Kasus Penguasaan Hutan Noge di Tanaloran Flores. Insani, 15 (2) : 1-11.

Nair, R., 1993. An Introduction to Agroforestry. Kluver Academic PublisherBoston in cooperative with International Centre for Research in Agroforestry.

Nazir, M., 2009. Metode Penelitian. Cetakan ke-7. Ghalia Indonesia. Bogor.

Nugraha, A., 1999. Latar Belakang konflik Sosial di Sektor Kehutanan: Suatu Tinjauan dari Perspektif Antropolog. Makalah pada Pelatihan Upaya Pemberdayaan Masyarakat Melalui Program PMDH dan Koperasi. 28 Oktober 1999. Samarinda.

Pruitt, D.G. dan Rubin, J.Z., 2009. Teori Konflik Sosial. Pustaka Pelajar. Yogyakarta.

Purwanti, R., 2007. Pendapatan Petani Dataran Tinggi Sub DAS Malino Studi Kasus Kelurahan Gantarang Kabupaten Gowa. Jurnal Penelitian Sosial dan Ekonomi Kehutanan, 4(3):257-269

Rahmat, M., 2011. Peran Sektor Kehutanan dalam Perekonomian Kabupaten Ogan Komering Ulu Selatan. Jurnal Penelitian Sosial dan Ekonomi Kehutanan, 8 (2) : 110-121.

Safitri, M.A,Muhshi, M.A.,Muhajir, M., Shohibuddin, M., Arizona, Y., Sirait, M., Nagara, dan Santoso, H., (2011). Menuju kepastian dan keadilan tenurial (Edisi revisi). Epistema Institute. Jakarta:

Senoaji, G., 2009. Kontribusi Hutan Lindung terhadap Masyarakat Sekitarnya : Studi Kasus di Desa Air Lanang Bengkulu. Jurnal Manusia dan Lingkungan, 16 (1):12-22.

Senoaji, G., 2011. Perilaku Masyarakat Baduy dalam Mengelola Hutan Lahan dan Lingkungan di Banten Selatan. Humaniora, 23 (1) : 14-25.

Senoaji, G., 2012. Pengelolaan Lahan dengan Sistem Agroforestry oleh Masyarakat Baduy di Banten Selatan. Jurnal Bumi Lestari, XII (2):283293. 
Sylviani dan Hakim, I., 2014. Analisis Tenurial dalam Pengembangan Kesatuan Pengelolaan Hutan (KPH) : Studi Kasus KPH Gedong Wani Provinsi Lampung. Jurnal Penelitian Sosial dan Ekonomi Hutan, 11 (4) : 309-322.

Simon, H., 2001. Pengelolaan Hutan Bersama Rakyat (Cooperative Forest Management) Teori dan Aplikasi pada hutan Jati di Jawa. Bigraf Publishing. Yogyakarta.

Simon, H., 2007. Menatap kedepan Kehutanan Indonesia dalam Membangun $\mathrm{KPH}$ : Keharusan untuk Hutan Indonesia Lestari. Debut Press. Yogyakarta

Supratman, 2007. Pengembangan Usaha Masyarakat di dalam Kawasan Hutan (Studi Kasus Masyarakat Desa-Desa Sekitar Areal IUPHHK di Kabupaten Mamuju, Provinsi Sulawesi Barat). Jurnal Hutan dan Masyarakat, 2 (3):303-312

Supyan, 2011. Pengembangan Daerah Konservasi sebagai Tujuan Wisata. Jurnal Mitra Bahari. 5 : 53-69

Triwanto, J., Syarifuddin, A., Mutaqin T., 2012. Aplikasi Agroforestry di Desa Mentaraman Kecamatan Donomulyo Kabupaten Malang. Dedikasi. 9 (1) : 13-21.

Ulya, NA, Warsito, SP, Andayani, W, dan Gunawan, T. 2014. Nilai Ekonomi Air untuk Rumah Tangga dan Transportasi, Studi Kasus di Desa Desa sekitar Hutan Rawa Gambut Merang Kepayang, Sumatera Selatan. Jurnal Manusia dan Lingkungan. 21 (2) : 232-238.

Wibowo, A., 2013. Kajian Penurunan Emisi Gas Rumah Kaca Sektor Kehutanan untuk Mendukung Kebijakan Perpres No. 61 tahun 2011. Jurnal Analisis Kebijakan Kehutanan. 10 (3): 235-254

Yusran dan Abdulah, N., 2007. Tingkat Ketergantungan Masyarakat terhadap Kawasan Hutan di Desa Borisallo Kecamatan Parangloe Kabupaten Goa Sulawesi Selatan. Jurnal Hutan dan Masyarakat. 2 (1):127-135.

Zubayr, M, Darusman, D, Nugroho, B, dan Nurrohmat, DR. 2014. Peranan dalam Pihak dalam Implementasi Kebijakan Penggunaan Kawasan Hutan untuk Pertambangan. Jurnal Analisis Kebijakan Kehutanan. 11 (3) : 203-213. 